九州大学学術情報リポジトリ

Kyushu University Institutional Repository

\title{
Numerical simulation of fatigue crack propagation under biaxial tensile loadings with phase differences
}

Gotoh, Koj i

Department of Marine Systems Engineering, Kyushu University

Niwa, Toshio

Maintenance Research Technology Group, National Maritime Research Institute

Anai, Yosuke

海上·港湾・航空技術研究所

http://hdl. hand le. net/2324/4751319

出版情報: Marine structures. 42, pp.53-70，2015-07. International Ship and 0ffshore Structures Congress

バージョン：

権利関係 : 


\section{Numerical simulation of fatigue crack propagation under biaxial tensile loadings with phase differences}

\section{Koji GOTOH*}

Department of Marine Systems Engineering, Kyushu University, 744 Motooka, Nishiku, Fukuoka, 819-0395, Japan

Toshio NIWA

Maintenance Research Technology Group, National Maritime Research Institute, 6-381 Shinkawa, Mitaka, Tokyo, 181-0004, Japan

Yosuke ANAI

Structural Analysis and Processing Research Group, National Maritime Research Institute, 6-38-1 Shinkawa, Mitaka, Tokyo, 181-0004, Japan

* Corresponding author (Koji GOTOH)

(Phone) $+81-92-802-3457$

(Fax.) $+81-92-802-3368$

(Email)gotoh@nams.kyushu-u.ac.jp 


\section{ABSTRACT}

Fatigue crack propagation under the biaxial tensile loading, which loading directions are normal and parallel to the initial crack position, is highlighted in this study. Most of in-service structures and vessels are subjected to many types of loading. Generally, these loadings have different axial components with different phases. However, the structural integrities of structures and vessels are evaluated according to design codes based on theoretical and experimental investigations under a uniaxial loading condition. Most of these codes are based on the S-N curves approach. An approach that does not use S-N curves has been favored by researchers, with the fracture mechanics approach preferred for evaluating the fatigue life of structures. An advanced fracture mechanics approach was developed based on the Re-tensile Plastic zone Generating (RPG) stress criterion for fatigue crack propagation. In this study, fatigue crack propagation tests under biaxial loading with six different phase and loading conditions are performed and the effect of the phase difference under biaxial loading is evaluated. A numerical simulation method of fatigue crack propagation based on the RPG stress criterion under different biaxial loading phase conditions is presented and compared to measured data.

\section{Keywords}

Fatigue; fatigue crack growth; biaxial fatigue; phase difference; Strip yield mode; RPG stress criterion 


\section{INTRODUCTION}

Most of in-service structures and vessels are subjected to many types of loading. Generally, these loadings have different axial components and different phases. In practice, however, the structural integrity of most working structures are assessed by following the design codes of each structure, which are based on theoretical and experimental investigations under uniaxial loading conditions.

Fatigue strength under biaxial loading has been investigated via S-N curve and fracture mechanics approaches. The researches based on the fracture mechanics approach [1]-[4] could not reach a definite conclusion regarding the effect of biaxial loading on fatigue crack growth behavior because of conflicting results. However, the research based on the S-N curves [5] [6] gave only measured S-N curves for individual loading conditions. Hence, it is very important to establish a quantitative evaluation procedure for fatigue crack growth under biaxial loading conditions.

Authors have been favoring the advantage of the fracture mechanics approach for evaluating the fatigue life of structures, using an advanced fracture mechanics approach based on the Re-tensile Plastic zone Generating (RPG) stress criterion for fatigue crack propagation was developed by Toyosada et al. [7]. Moreover, they developed a numerical simulation code of fatigue crack propagation, which considered the fatigue crack opening / closing phenomena caused by crack wake over crack surfaces and implemented the RPG stress criterion as the fatigue crack propagation law. The validity of the estimated fatigue crack propagation histories under stress conditions of variable amplitude was confirmed by 
measured fatigue crack growth curves [7]. These comparisons, however, were performed under uniaxial loading conditions. The aim in this study was to extend this approach to biaxial loading problems, which loading directions are normal and parallel to the initial crack position, by evaluating the structural integrity related to the fatigue strength from a practical point of view.

Fatigue crack propagation tests under biaxial loading with six different phase conditions were performed in order to highlight the effect of the phase difference under biaxial loading on the fatigue crack growth behavior. A numerical simulation method of fatigue crack propagation based on the RPG criterion under biaxial loading with different loading phases is proposed.

\section{FATIGUE CRACK PROPAGATION TEST UNDER BIAXIAL LOADING}

\subsection{Overview of the experiment}

Cruciform-shaped cracked specimens shown in Fig.1 were prepared for fatigue crack propagation tests under biaxial loading conditions. In addition, a center-cracked tensile (CCT) specimen shown in Fig.2 was prepared for the test under uniaxial loading conditions. All the specimens were formed from the same mild steel plate (grade KA standardized by classification society ClassNK). The chemical composition and mechanical properties of the tested steel are listed in Table 1. Fatigue crack propagation tests under biaxial loading conditions were performed by using a testing system that consisted of four independent servo loading actuators that enabled controlled variable loading under different phases, see Fig.3. The 
applied loading conditions for each specimen are listed in Table 2 and the schematic illustration of load waveforms are shown in Fig.4.

\subsection{Fractured surface observations}

It is generally accepted that fatigue crack opening / closing behavior is induced by the plastic deformed layer (crack wake) over the fatigued crack surfaces. However, the roughness of the crack surface also plays a role in inducing the crack closure.

The fractured crack surfaces were observed by low-voltage scanning electron microscopy (LV-SEM) to investigate the degree of contribution of such crack closure induced mechanisms under biaxial loading with different loading phases. The observed crack surfaces are shown in Fig. 5. The surfaces observed were about $20 \mathrm{~mm}$ from the tip of the initial notch. Little difference of each biaxial specimen was confirmed in fractured surface characteristics even though each loading condition of the experiment had the phase difference, see Fig. 5. Additionally, these surfaces were compared with the CCT specimen and similar surface characteristics were confirmed. These observations indicate that the fatigue crack closure of biaxial specimens is induced by the crack wake over the crack surfaces and the phase difference of biaxial loading does not affect significantly the formation of the fractured surfaces. 


\subsection{Stress intensity factor of the cruciform-shaped cracked specimen}

The stress intensity factors of the cruciform-shaped cracked specimen subjected to biaxial loading with different phases were calculated by the J integral method. Commercial FE software MSC Marc 2011[8] was applied to calculate the value of the $\mathrm{J}$ integral. FE mesh subdivisions are shown in Fig.6. Minimum mesh size along a crack line is $1.0 \mathrm{~mm} \times 1.0 \mathrm{~mm}$. Four nodes isoparametric element were applied to establish FE mesh data. The same FE software and mesh idealizations were applied to obtain stress distributions over a supposed crack propagation path in this research.

Figure 7 shows the calculation results. Each value of stress intensity factor was calculated under the applied loading condition shown in the insert. The unit of applied stress is MPa. The stress intensity factors of the CCT specimen [9] are also plotted. All the stress intensities of the cruciform-shaped specimen are lower than that of the CCT specimen and the value of the stress intensity decreases with the increase in the stress component of the crack line direction. The polynomial expression of the stress intensity by the least square fitting of the FE solution is as follows. In Eq. (1), the unit of the stress intensity factor $(K)$ is MPa $\mathrm{m}^{0.5}$ and that of the half crack length $(a)$ is $\mathrm{mm}$.

$$
K= \begin{cases}7.981 \times 10^{-11} a^{5}-3.270 \times 10^{-8} a^{4}+5.038 \times 10^{-6} a^{3}-3.440 \times 10^{-4} a^{2}+1.346 \times 10^{-2} a & :[\mathrm{C}-1] \\ 1.018 \times 10^{-10} a^{5}-4.175 \times 10^{-8} a^{4}+6.406 \times 10^{-6} a^{3}-4.400 \times 10^{-4} a^{2}+1.717 \times 10^{-2} a & :[\mathrm{C}-2] \\ 9.194 \times 10^{-11} a^{5}-3.769 \times 10^{-8} a^{4}+5.791 \times 10^{-6} a^{3}-3.970 \times 10^{-4} a^{2}+1.550 \times 10^{-2} a & :[\mathrm{C}-3, \mathrm{C}-4] \\ 1.170 \times 10^{-10} a^{5}-4.540 \times 10^{-8} a^{4}+6.603 \times 10^{-6} a^{3}-4.300 \times 10^{-4} a^{2}+1.598 \times 10^{-2} a & :[\mathrm{C}-5] \\ 1.331 \times 10^{-10} a^{5}-5.168 \times 10^{-8} a^{4}+7.494 \times 10^{-6} a^{3}-4.878 \times 10^{-4} a^{2}+1.804 \times 10^{-2} a & :[\mathrm{C}-6]\end{cases}
$$




\subsection{Measured fatigue crack propagation behavior}

The measured fatigue crack propagation curves of each cruciform specimen are shown in Fig. 8. Figure 9 shows the relationship between the fatigue crack propagation rates $(d a / d N)$ and the stress intensity factor range $(\Delta K)$. Stress intensity factors of each loading condition are calculated by Eq. (1). The measured results of the CCT specimen are also plotted for comparison. For negative value of the stress ratio of crack line vertical component $\left(R=\sigma_{x 0}{ }^{\min } / \sigma_{x 0}{ }^{\max }\right)$, the stress intensity factor range was obtained according to ASTM E-647 [10]. Figures 8 a) and 9 a) to 9 d) indicate that the fatigue crack propagation rate decreases as the phase difference is changed from $\pi$ to $\pi / 2$ and $3 \pi / 2$, and then to 0 under the same applied stress range. That is, the phase differences in the biaxial loading affect the fatigue crack growth behavior. Besides, figure $8 \mathrm{~b}$ ) indicates that the effect of applied stress range on the crack line vertical direction for the fatigue crack growth behavior depends on the phase difference of biaxial loading condition.

Figure 10 shows the applied stress range over a crack line of the cruciform-shaped specimen under nocrack conditions. Each stress range is obtained according to Eq. (2) which enables to convert the biaxial stress problem to the equivalent uniaxial stress problem. Although Eq. (2) is based on the Method of Takahashi et al. [6], the definition of each strain component in Eq. (2) is changed by authors. The values of $\varepsilon_{x}^{0}$ and $\varepsilon_{y}^{0}$ were obtained by the elastic FE analysis. The same FE mesh subdivision shown in Fig. 6 were applied. 


$$
\sigma_{x}^{e q}=\frac{E}{1-v^{2}}\left(\varepsilon_{x}^{0}+v \varepsilon_{y}^{0}\right)
$$

where,

$\sigma_{x}^{e q}$ : equivalent uniaxial stress normal to crack line under biaxial loading,

$\varepsilon_{x}^{0}: \quad$ vertical ( $x$-direction) component of strain at the center $(x=y=0)$ of specimen under no crack and uniaxial ( $x$-direction) loading condition,

$\varepsilon_{y}^{0}: \quad$ horizontal ( $y$-direction) component of strain at the center $(x=y=0)$

under no crack and uniaxial ( $y$-direction) loading condition,

$E: \quad$ Young's modulus and

$v: \quad$ poisson's ratio.

Figure 10 a) suggests that the equivalent uniaxial stress range normal to crack line under biaxial loading obtained by Eq. (2) $\left(\Delta \sigma_{x}^{e q}\right)$ of each biaxial loading condition decrease as $\phi$ changes in this order: $\pi, \pi / 2$ and $3 \pi / 2$, and 0 . Figure $10 \mathrm{~b}$ ) indicates that $\Delta \sigma_{x}{ }^{e q}$ under no-crack condition changes according to the phase difference of biaxial loading and that the effect of applied stress ranges in crack vertical direction for the fatigue crack propagation might be cancelled by the phase difference effect of biaxial loading condition. In addition, it is confirmed that the amount of $\Delta \sigma_{x}^{e q}$ under each loading condition is consistent to the fatigue crack propagation behavior shown in Figs. 8 and 9. Therefore, it is considered that this behavior of the applied stress range in the crack opening mode dominates the fatigue 
crack propagation rates. It is considered that the variety of $\Delta \sigma_{x}^{e q}$ shown in Fig.10 is derived from the compressive stress occurred along a crack line direction. However, this compressive stress might be changed to the tensile condition according to the geometrical condition of cracked bodies. In this case, $\Delta \sigma_{x}^{e q}$ shows larger than uniaxial loading condition and the acceleration effect of fatigue crack propagation rate is occurred.

Figure 11 shows growth histories of the plastic zone over a crack line ( $x=0$ in Fig.1) formed in the vicinity of crack tip by the elastic-plastic FE analyses. The same FE solver and mesh subdivision mentioned in former section was applied and the elastic-perfect plastic body was supposed as the stress versus strain relation of applied material.

Although the effect of fatigue crack surface contact for the plastic zone formation during the cyclic loading was ignored, it could be regarded as those corresponding to the plastic zone growth histories associated with the crack propagation in the sense of first approximation.

Because the fatigue crack driving force is supplied from the plastic hysteresis consumed in the vicinity of a crack tip, It is considered that the amount of alternating plastic zone size, which correspond to the difference of the plastic zone size between at the maximum loading to the minimum loading conditions, has a close relation to the degree of fatigue crack propagation rate. Figures 11 a) and b) indicate that the alternating plastic zone size of each biaxial loading condition decrease as $\phi$ changes in this order: $\pi, \pi / 2$ and $3 \pi / 2$, and 0 . In addition, Figs. $11 \mathrm{c}$ ) and d) indicates that the alternating plastic zone size changes 
according to the phase difference of biaxial loading and that the effect of applied stress ranges in crack

vertical direction for the fatigue crack propagation might be cancelled by the phase difference effect of biaxial loading condition. It is confirmed that the amount of alternating plastic zone size under each loading condition is consistent to the fatigue crack propagation behavior shown in Figs. 8 and 9.

\section{NUMERICAL SIMULATION OF FATIGUE CRACK PROPAGATION}

\subsection{Overview of numerical simulation based on the strip yield model [7]}

The numerical simulation of the fatigue crack propagation was performed by using our developed numerical simulation which models the fatigue crack opening/closing behavior and estimates the relationship between the fatigue crack length and the number of applied loading cycles. Applied numerical simulation model is based on the strip yield model with the stress intensity factor weight function. Although details of the theoretical background for this model can be found in reference [7], overview of this model is explained briefly according to reference.

The condition of the displacement continuity ahead of the physical crack tip is not satisfied in the primitive strip yield model. To eliminate this deficiency, the chink corresponding to the virtual crack opening displacement (COD) in the plastic zone ahead of a physical crack tip is plugged up by a small segment shown in Fig. 12. 
After loading the segment with uniform elastic stresses of the yield stress magnitude under an appropriate triaxial constraint condition, it deforms elastically to accurately fit the fictitious COD in the plastic zone of strip yield model, as indicated by the solid line in Fig. 12 b). Inserting the segments enables to satisfy the displacement continuity and improves the model performance compared to the original concept of the strip yield model. The advantage of this model's approach can be proved by considering Newman's crack closure model [11] [12] for which the segment material is assumed to be the rigid-plastic.

If the current tensile plastic zone extends beyond the previous plastic zone, the original strip yield model should be satisfied. A layer of the residual tensile deformations, which is commonly known as the crack wake, generated by the previous loading is on fatigue crack surfaces. The thickness of the layer $L_{j}$ is assumed to equal length of the segment after removing the applied stress, because the perfect elasticplastic material of the layer is assumed.

$$
L_{j}=V_{j} /\left(1+\lambda \sigma_{Y} / E^{\prime}\right)
$$

where

$L_{j}: \quad$ thickness of the plasticity elongated (crack wake) layer at $x_{j}$,

$V_{j}: \quad$ crack opening displacement (COD) at $x_{j}$

$x_{j}: \quad$ reference point on the $x$ axis

$\sigma_{Y}: \quad$ Material yield strength,

$\lambda$ : $\quad$ plastic constraint factor and 


$$
E^{\prime}=\left\{\begin{array}{cc}
E & {[\text { Plane stress }]} \\
E /\left(1-v^{2}\right) & {[\text { Plane strain }]}
\end{array} .\right.
$$

If the present plastic zone is embedded in the previous plastic zone, the superposition principle shown in

Fig. 13 is satisfied based on the strip yield model and the following relations are introduced.

$$
V_{j}=P \sum_{i=1}^{n} s_{i} F\left(x_{j}, x_{i}, a^{*}\right)-\sum_{i=1}^{n} \sigma_{i} F\left(x_{j}, x_{i}, a^{*}\right)+\sum_{i=1}^{n} \sigma_{i}^{R} F\left(x_{j}, x_{i}, a^{*}\right),
$$

where

$P: \quad$ magnitude of the external load,

$s_{i}: \quad$ working stress at $x_{i}$ per unit external loading under no crack condition,

$F\left(x_{j}, x_{i}, a^{*}\right): \quad \mathrm{COD}$ at $x_{j}$ when a uniform unit stress acts between $x=B_{i}$ and $B_{i+1}$ on the crack surfaces, $x_{i}=\left(B_{i}+B_{i+1}\right) / 2$,

$a^{*}: \quad$ length of the fictitious crack (tip of the tensile plastic zone),

$\sigma_{I}: \quad \quad$ working stress at $x_{i}$ along the crack line and

$\sigma_{i}^{R}: \quad$ pre-existing residual stress at $x_{i}$.

If an element remains elastic, the following relation should be satisfied in the fictitious crack region and the crack closure region.

$$
L_{j}=V_{j} /\left(1+\sigma_{j} / E^{\prime}\right)
$$


By substituting Eq. (4) into Eq. (5), $\sigma_{j}$ can be obtained by solving the resulting linear system of equations through an iterative method with the following constraints:

For the region ahead of the crack tip,

$$
\begin{aligned}
& \text { if } \sigma_{j}<-\lambda \sigma_{Y} \text {, then } \sigma_{j}=-\lambda \sigma_{Y} \\
& \text { and } \\
& \text { if } \sigma_{j}<\lambda \sigma_{Y} \text {, then } \sigma_{j}=\lambda \sigma_{Y}
\end{aligned}
$$

For the plastic wake zone,

$$
\begin{aligned}
& \text { if } \sigma_{j}>0 \text {, then } \sigma_{j}=0 \\
& \text { and } \\
& \text { if } \sigma_{j}<-\lambda \sigma_{Y} \text {, then } \sigma_{j}=-\lambda \sigma_{Y}
\end{aligned}
$$

From the solution of $\sigma_{j}, \mathrm{COD}$ is obtained by Eq. (4) at the minimum external load during the cyclic loading $\left(P_{\min }\right)$ or the maximum one $\left(P_{\max }\right)$ if the tensile plastic zone is inside the previous tensile plastic zone. The RPG stress is obtained when the stress in the bar element adjacent to a crack tip reaches the yield stress during the loading reversal. The crack opening load is obtained when the stress in the bar element adjacent to a crack tip is equal to zero during the loading reversal.

\subsection{Equivalent distributed stress method}


Our numerical simulation code of fatigue crack propagation cannot be applied directly to the cruciformshaped specimen or to arbitrary geometrical-shaped joints with a crack or cracked structures because explicit expressions of the weight function of the stress intensity factor for such joints or structures have not yet been established. An alternative method, the Equivalent Distributed Stress (EDS) method [13] for estimating the fatigue crack propagation histories was proposed. Calculation flow by applying EDS method is as follows.

1) Obtaining the relationship between the fatigue crack length and stress intensity factor of the object.

2) Transformation of $a-K$ relationship into the EDS as a function of crack length. EDS enables the stress field near the crack tip of planar cracks in an infinite wide plate with a through thickness crack to reproduce. EDS must satisfy the following equation,

$$
\frac{2}{\sqrt{\pi a}} \int_{0}^{a} \frac{\sigma_{E D S}(x)}{\sqrt{1-(x / a)^{2}}} d x=K_{\text {object }}(a)
$$

where

$$
\begin{aligned}
& \sigma_{E D S}(x): \quad \text { EDS at } x_{i} \text { and } \\
& K_{\text {object }}(a): \quad \text { stress intensity factor of the object at crack length } a .
\end{aligned}
$$

3) Performing the numerical simulation of fatigue crack growth for an infinite wide plate with a through thickness crack the condition that EDS is distributed along a crack line. 
EDS for the cruciform shaped specimen under uniaxial unit remote loading normal to the crack line is shown in Fig.14.

Before applying the EDS method to estimate the fatigue crack propagation in the cruciform-shaped specimen, the $a-K$ relation of the object must be determined. Figure 15 shows the $a-K$ relation of each biaxial loading condition. The maximum and minimum stress intensity values are plotted for each case as a function of fatigue crack length. The FE analysis values (circles and triangles) were obtained by finite element analysis with the $\mathrm{J}$ integral method. The same FE solver and mesh subdivision mentioned in former section was applied and applied biaxial loads that incorporated the phase difference.

The solid and dashed curves in Fig. 15 were obtained by using a simplified and more practical method described below.

1) Calculate the value of stress intensity factors and EDS under uniaxial unit remote loading normal to the crack line shown in Fig. 14.

2) Correct for the difference between the biaxial condition and uniaxial condition by considering the difference of the stress component over the crack line shown in Fig. 10.

The good agreement of $a-K$ relationship obtained by above mentioned procedure with FE analyses shown in Fig. 15 indicates that the simple treatment mentioned above gives a good approximation of the $a-K$ relationship. 
Next, the numerical simulations of fatigue crack propagation was conducted by using the procedure mentioned in former section with the EDS method. Figure 16 shows a comparison between the estimated results and the measured ones. The EDS method with simple $a-K$ relationship estimation mentioned above reproduced well the measured fatigue crack propagation histories under different biaxial phase loading conditions.

On the other hand, the cruciform-shaped specimen is approximated as a CCT specimen whose width is equal to the minimum width of the cruciform-shaped specimen $(200 \mathrm{~mm})$ from the point of simplified simulation of the fatigue crack propagation under biaxial loading. The effect of the phase difference of the applied biaxial loads is based on the applied stress range conversion shown in Fig. 10. Dashed curves shown in Fig. 16 are the results of the numerical simulation by the CCT approximation. All the results give the safe side fatigue crack propagation histories. The difference between the estimated and measured results is affected by the difference in the ligament size between the CCT specimen and the cruciformshaped specimen because the fatigue crack driving energy comes from the plastic hysteresis that occurs in the plastic zone near the crack tip [7] and the plastic zone grows faster for a small ligament size.

\section{CONCLUDING REMARKS}

Fatigue crack propagation tests under biaxial loading with different phase conditions were performed and the effect of the phase difference on the fatigue crack propagation under biaxial loading was evaluated. A 
numerical simulation method of fatigue crack propagation under biaxial load with different loading phases is proposed, which is based on the EDS method and the conversion method of the biaxial loading condition with phase difference to an equivalent uniaxial loading condition. The method was validated by comparing the estimated fatigue crack propagation histories with the measured ones.

In the future we plan to extend this research as follows.

1) Verification of our proposed estimation method for the case where both phase and applied stress range vary.

2) Quantitative estimation of fatigue crack growth history for many types of welded joints under biaxial loadings.

\section{Acknowledgements}

This paper owes much to the thoughtful and helpful supports of Mr. Tetsuya Omori, former graduate student of Kyushu University, Mr. Koji Murakami, senior technician of Kyushu University and Mr. Yoshihisa Tanaka, National Maritime Research Institute, Japan.

This research was funded by a Grant-in-Aid for Young Scientists (S) (No. 21676007) from the Japan Society for the Promotion of Science.

The authors would like to express their appreciation to Nippon Steel \& Sumitomo Metal Corporation for supplying the steel plates for the specimens. 


\section{REFERENCES}

[ 1 ] Hoshide, T., Tanaka, K. and Yamada, A. (1981) Stress-Ratio Effect of Fatigue Crack Propagation in a Biaxial Stress Field, Fatigue of Engineering Materials and Structures, 4(4), 355-366.

[ 2 ] Yuuki, R., Kitagawa, H., Tohgo, K. and Tanabe, M. (1984) Effect of Bi-Axial Stress on Fatigue Crack Growth, Zairyo (Materials Science Research), 33(373), 1271-1277. (in Japanese)

[ 3 ] Brown, M.W. and Miller, K.J. (1985) Mode I Fatigue Crack Growth under Biaxial Stress at Room and Elevated Temperature, Multiaxial Fatigue (ASTM STP 853), 135-152.

[ 4 ] Yuuki, R., Akita, K. and Kishi, N. (1988) Effect of Biaxial Stress Condition and its Change on Fatigue Crack Growth Properties, Zairyo (Materials Science Research), 37(420), 1084-1089. (in Japanese)

[ 5 ] Sonsino, C.M. (1995) Multiaxial fatigue of welded joints under in-phase and out-of-phase local strains and stresses, Int. J. Fatigue, 17(1), 55-70.

[ 6 ] Takahashi, I., Ushijima, M., Takada, A., Akiyama, S. and Maenaka, H. (1999) Fatigue behavior of a box-welded joint under biaxial cyclic loads, Fatigue Fract. Engng. Mater. Struct., 22(10), 869-877.

[ 7 ] Toyosada, M., Gotoh, K. and Niwa, T. (2004) Fatigue crack propagation for a through thickness crack: a crack propagation law considering cyclic plasticity near the crack tip, Int. J. Fatigue, 26(9), 983992.

[ 8 ] http://www.mscsoftware.com/Products/CAE-Tools/Marc.aspx. 
[ 9 ] Tada, H., Paris, P.C. and Irwin, G.R. (2000) The Stress Analysis of Cracks Handbook, 3rd Ed., ASME Press, New York.

[ 10 ] ASTME647-08 (2008) Standard Test Method for Measurement of Fatigue Crack Growth Rates.

[11 ] Newman, Jr. J.C. (1981) A Crack-Closure Model for Predicting Fatigue Crack Growth under Aircraft Spectrum Loading, NASA Tech. Memo., 81941.

[12] Newman Jr. J.C. (1992) FASTRAN-II: A FATIGUE CRACK GROWTH STRUCTURAL ANALYSIS PROGRAM, NASA Tech. Memo., 104156.

[ 13 ] Toyosada, M., Gotoh, K. and Niwa, T. (2004) Fatigue life assessment for welded structures without initial defects: an algorithm for predicting fatigue crack growth from a sound site, Int. J. Fatigue, 26(9), 993-1002. 


\section{FIGURE CAPTIONS}

Fig.1 Configuration of the cruciform shaped cracked specimen.

Fig.2 Configuration of the center cracked tensile (CCT) specimen.

Fig.3 Set-up of fatigue crack propagation test under biaxial tensile loading.

Fig.4 Schematic illustration of applied biaxial loading waveform

Fig.5 Photographs of fatigue fractured surfaces.

Fig.6 Finite element subdivision of the cruciform shaped cracked specimen.

Fig.7 Stress intensity factors of the cruciform shape cracked specimen under the biaxial loading with different phases.

Fig.8 Fatigue crack propagation curves.

Fig.9 Relationship between stress intensity factor range and fatigue crack propagation rate.

Fig. 10 Effect of phase difference on the stress histories over a supposed crack line.

Fig. 11 Plastic zone size growth histories.

Fig.12 Schematic illustration of the crack surface displacements for the fictitious crack from the strip yield model and the approximation of the physical COD.

Fig.13 Application of the superposition principle to computed COD in the plastic zone embedded in the previous plastic zone.

Fig.14 Equivalent distributed stress (EDS) under uniaxial loading condition of the cruciform shape cracked specimen used. 
Fig.15 Comparisons of stress intensity factor histories based on EDS approximations with FE analyses.

\section{TABLE CAPTIONS}

Table 1 Mechanical Properties and chemical composition of tested material (ClassNK: grade KA).

Table 2 Applied loading conditions 

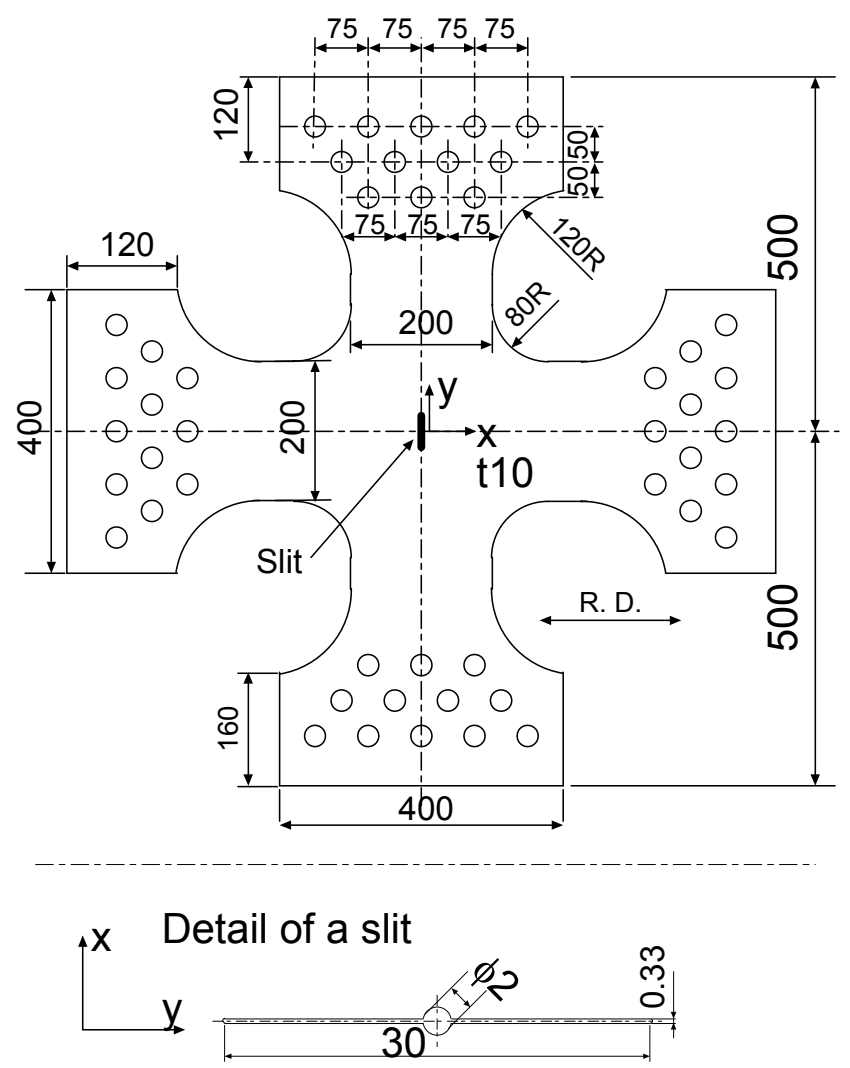

(Notes)

$x$ : coordinate normal to the crack line defined as the vertical direction in this paper.

$y$; coordinate parallel to the crack line defined as the horizontal direction in this paper.

Fig.1 Configuration of the cruciform shaped cracked specimen

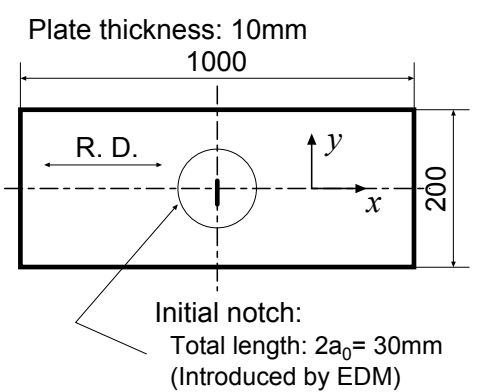

Fig.2 Configuration of the center cracked tensile (CCT) specimen. 


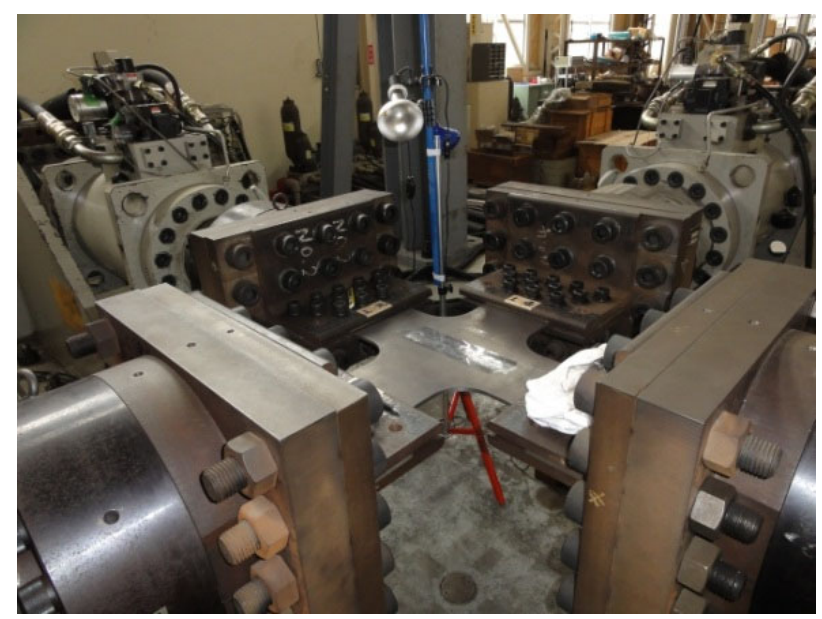

Fig.3 Set-up of fatigue crack propagation test under biaxial tensile loading. 


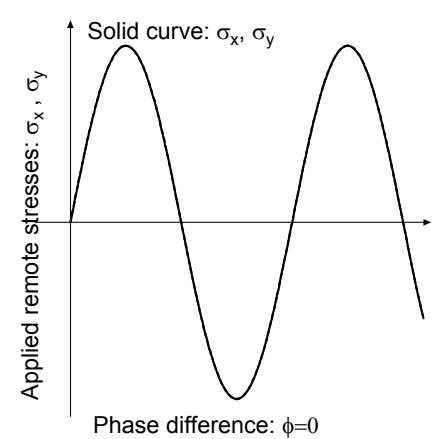

Test ID: C-1

Solid curve: $\sigma_{\mathrm{x}}$

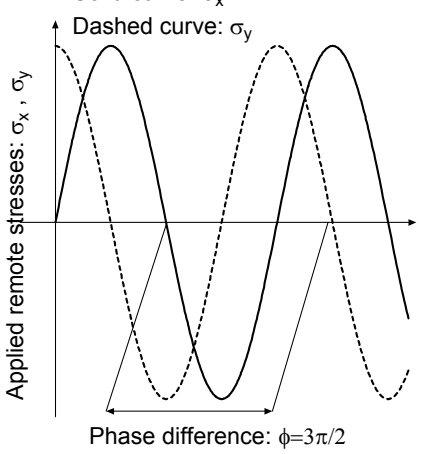

Test ID: C-4

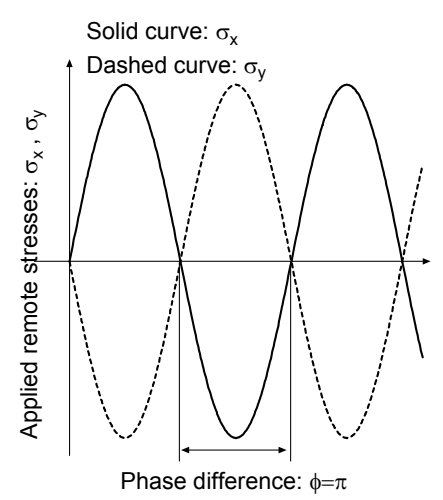

Test ID: C-2

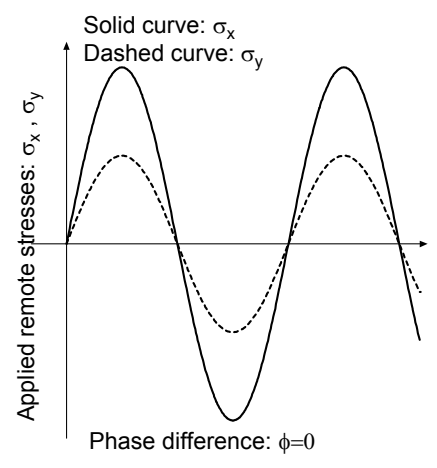

Test ID: C-5

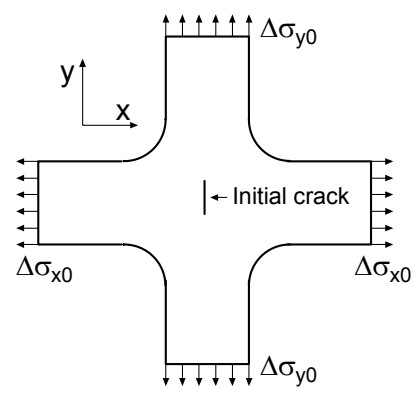

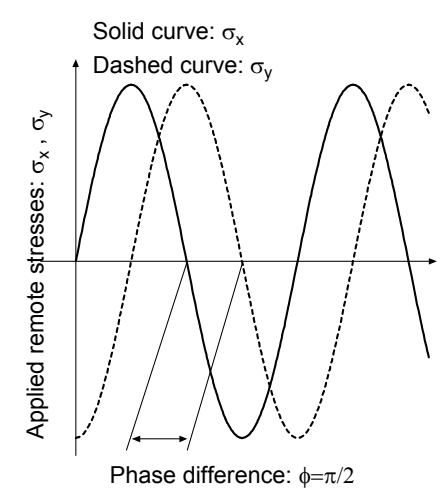

Test ID: C-3

Solid curve: $\sigma_{\mathrm{x}}$

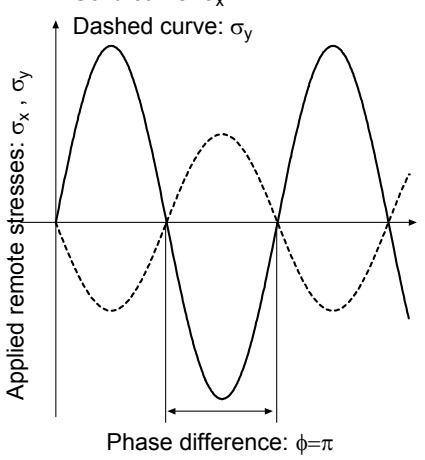

Test ID: C-6

(Notes)

$\Delta \sigma_{x 0}: \quad$ applied remote stress range normal to the crack line.

$\Delta \sigma_{y 0}: \quad$ applied remote stress range of the crack line direction.

Fig.4 Schematic illustration of applied biaxial loading waveforms. 


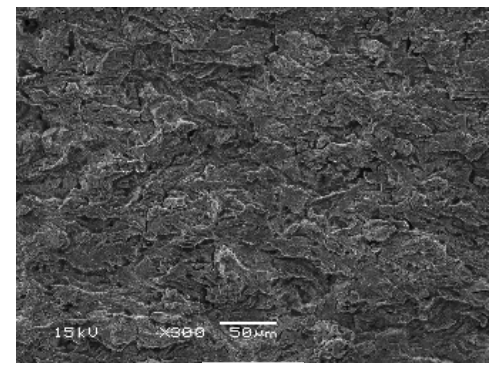

a) $\mathrm{C}-1$

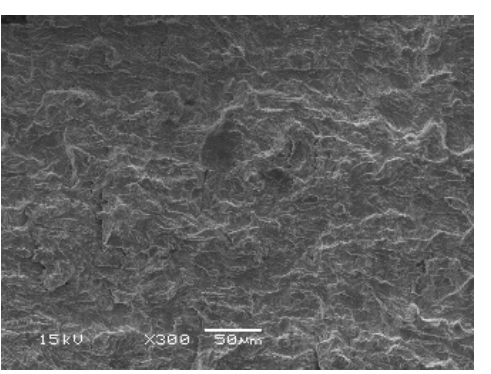

c) $\mathrm{C}-3$

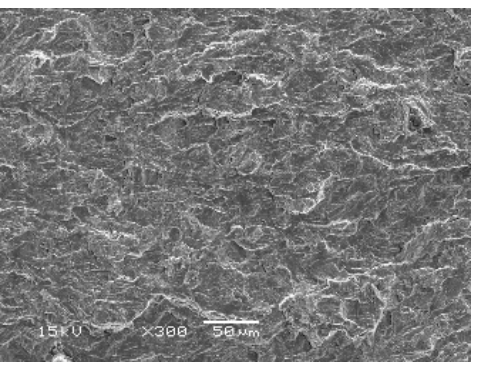

e) C-5

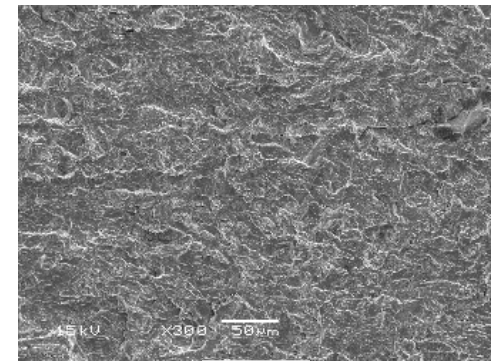

b) $\mathrm{C}-2$

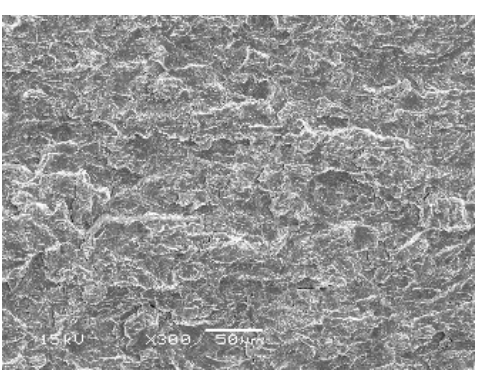

d) $\mathrm{C}-4$

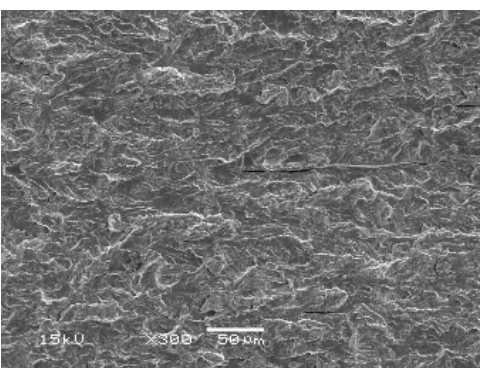

f) $\mathrm{C}-6$

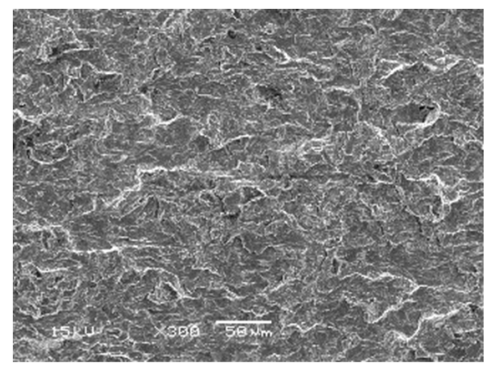

g) $\mathrm{CCT}$

Direction of crack propagation.

Fig.5 Photographs of fatigue fractured surfaces. 


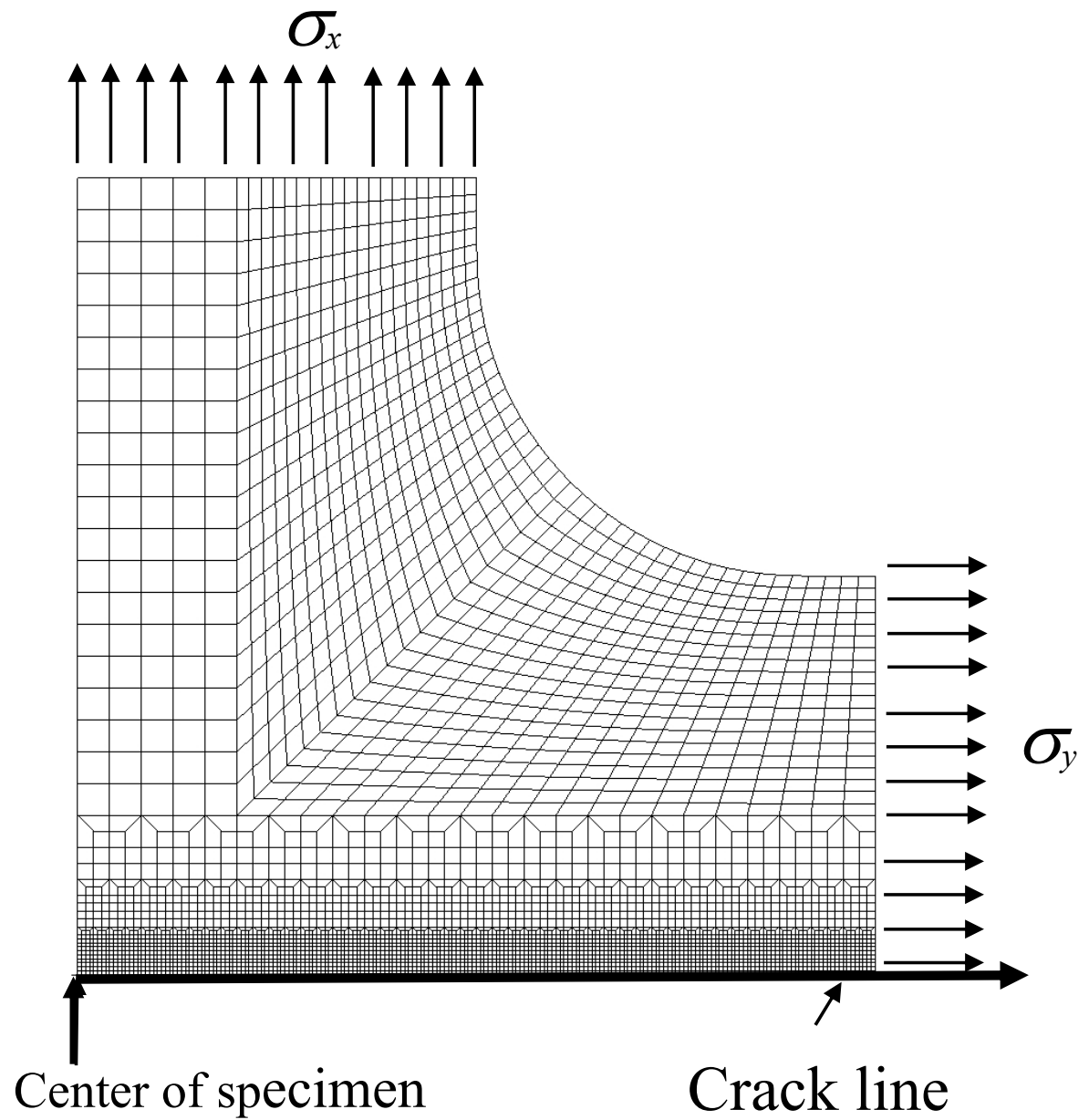

Fig.6 Finite element subdivision of the cruciform shaped cracked specimen. 


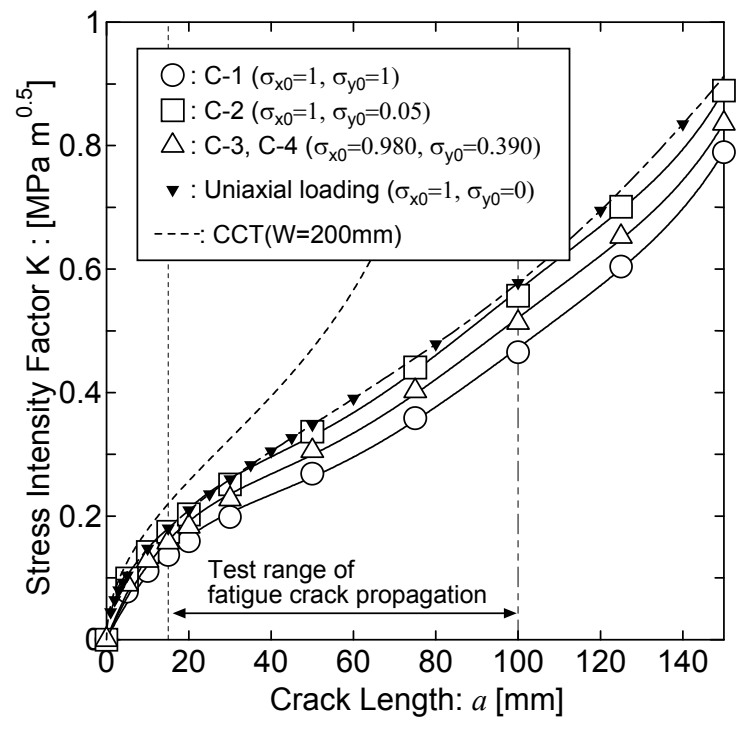

a) $\Delta \sigma_{x 0} / \Delta \sigma_{y 0}=1$

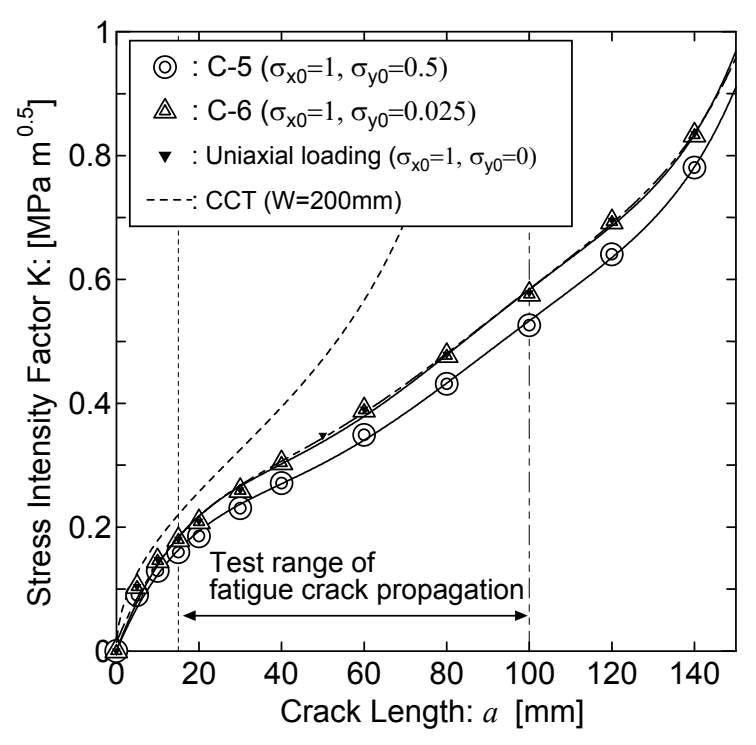

b) $\Delta \sigma_{x 0} / \Delta \sigma_{y 0}=2$

Fig.7 Stress intensity factors of the cruciform shape cracked specimen under the biaxial loading with different phases.

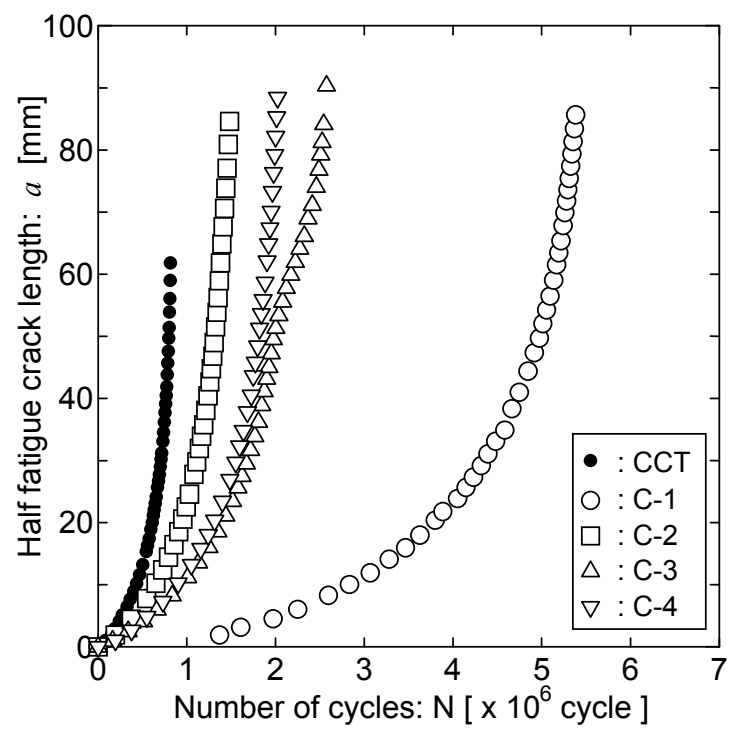

a) Effect of the phase difference

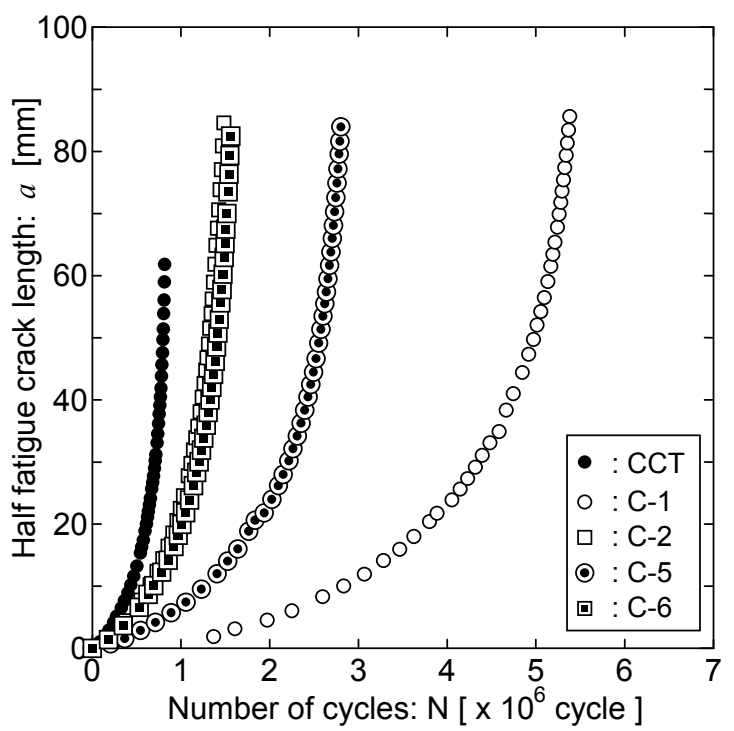

b) Combined effects of the phase and range of loading

Fig.8 Fatigue crack propagation curves. 


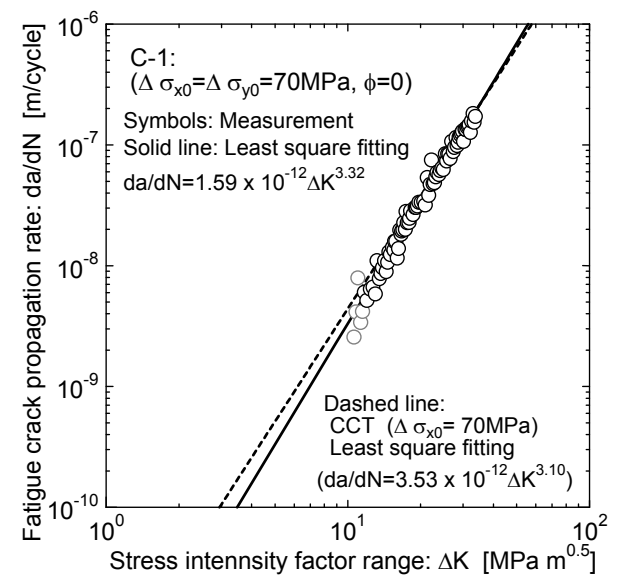

a) $\mathrm{C}-1$

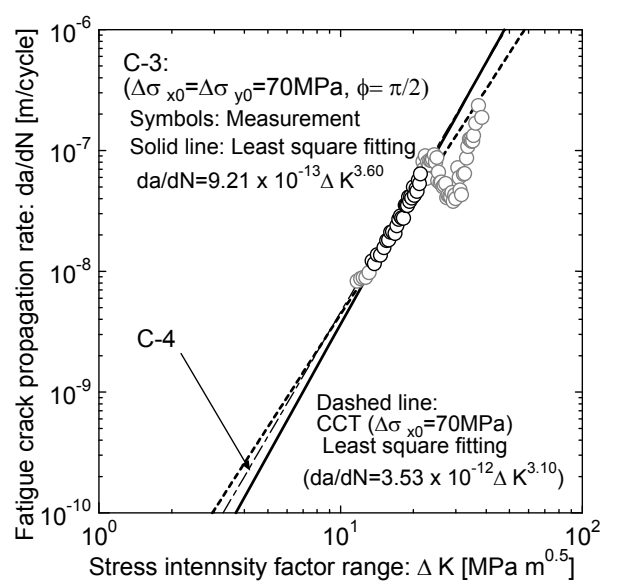

c) $\mathrm{C}-3$

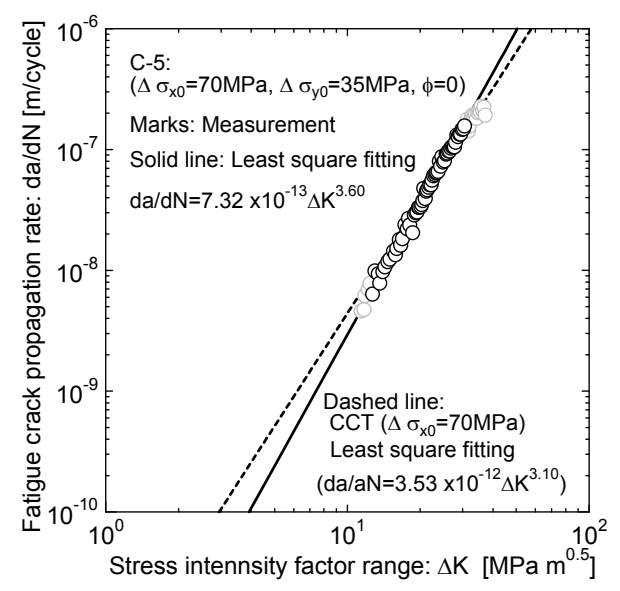

e) $\mathrm{C}-5$

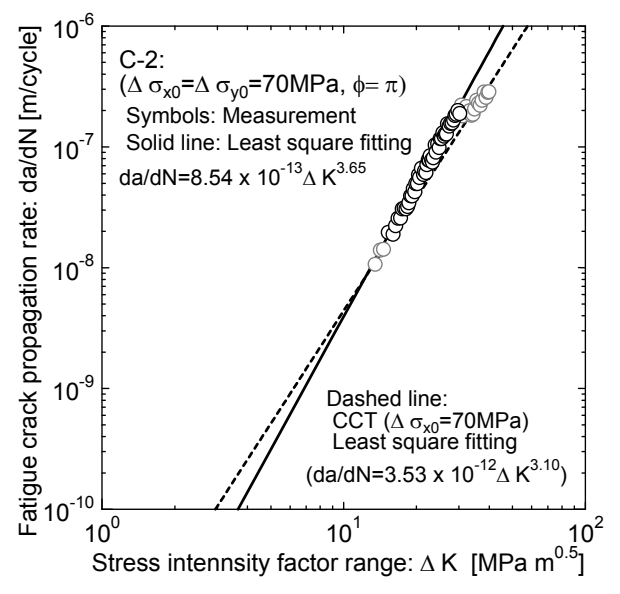

b) $\mathrm{C}-2$

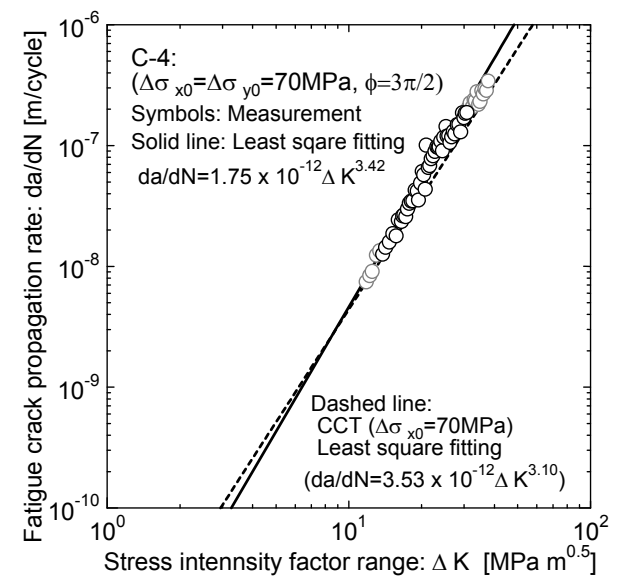

d) $\mathrm{C}-4$

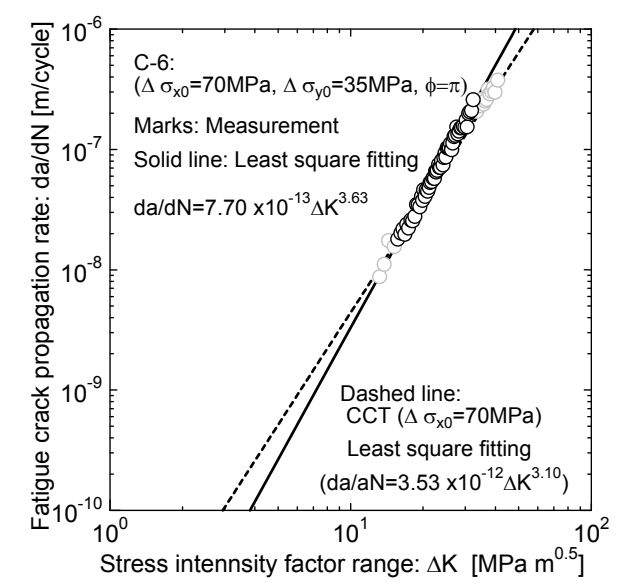

f) C-6

Fig.9 Relationship between stress intensity factor range and fatigue crack propagation rate. 


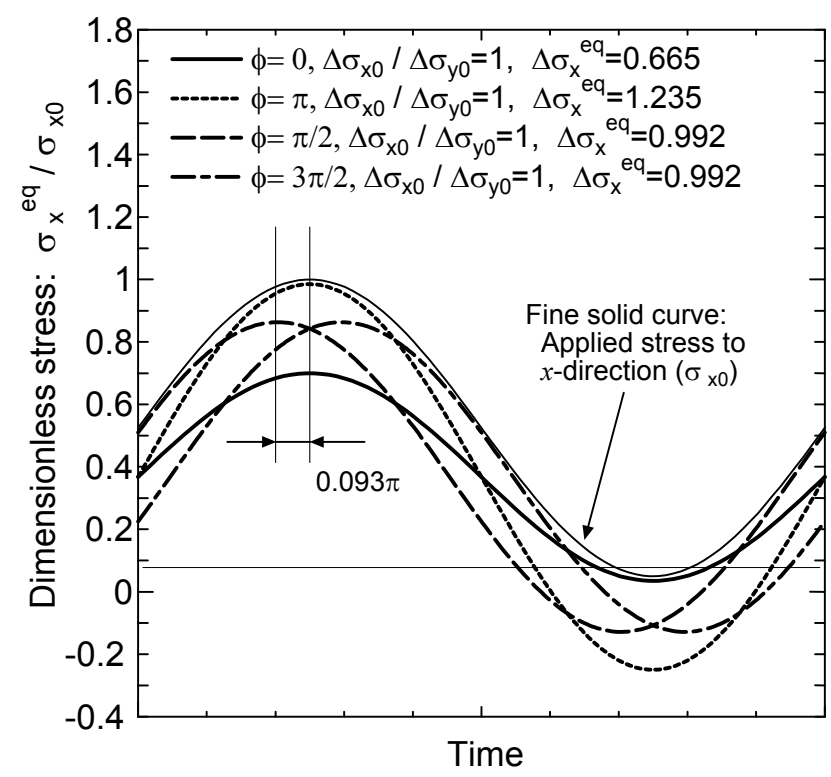

a) Effect of the phase difference

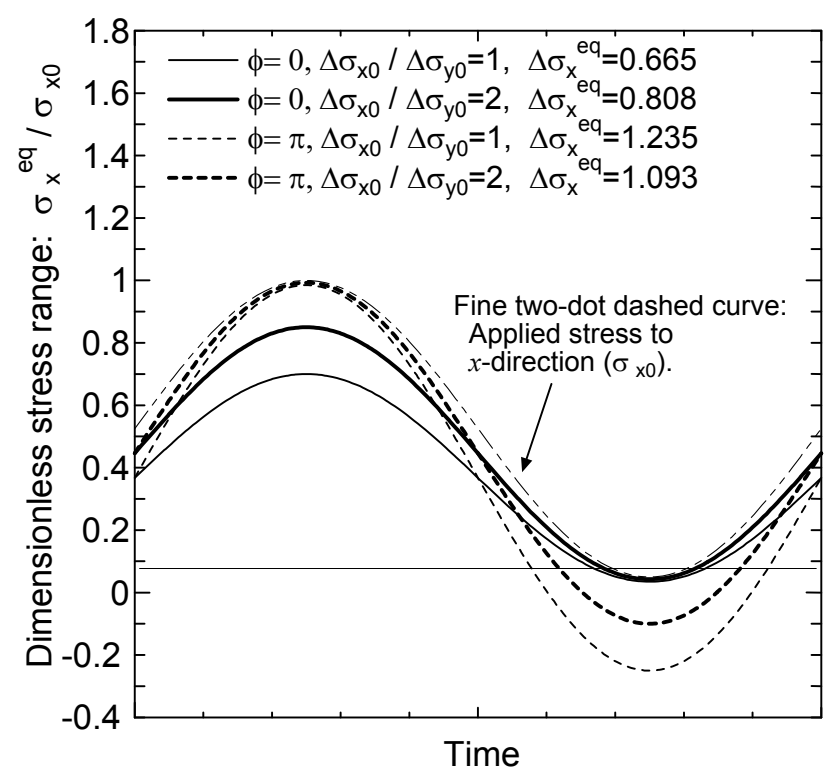

b) Combined effects of the phase and range of loading

Fig.10 Effect of phase difference on the stress histories over a supposed crack line. 


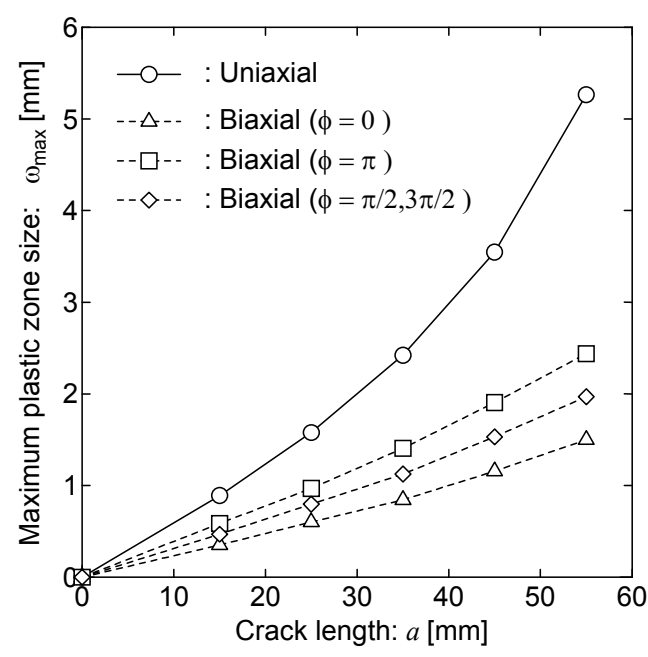

a) At the maximum loading,

$\Delta \sigma_{x 0} / \Delta \sigma_{y 0}=1$.

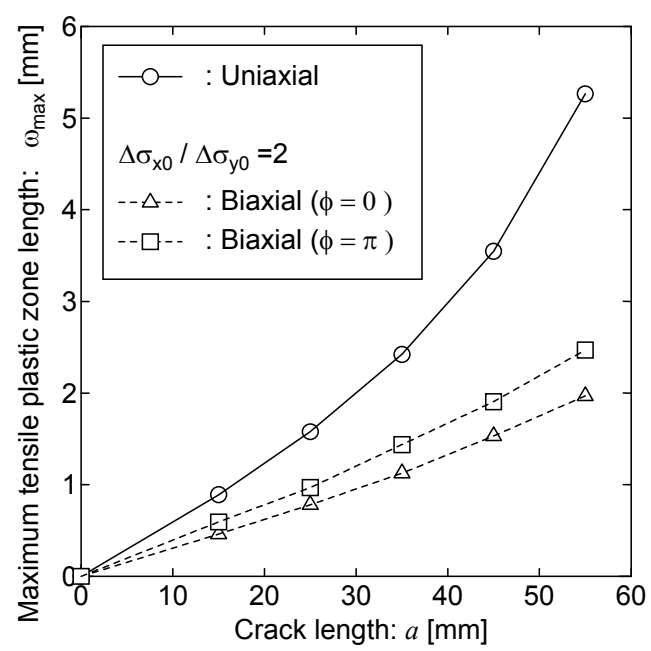

c) At the maximum loading,

$$
\Delta \sigma_{x 0} / \Delta \sigma_{y 0}=2 .
$$

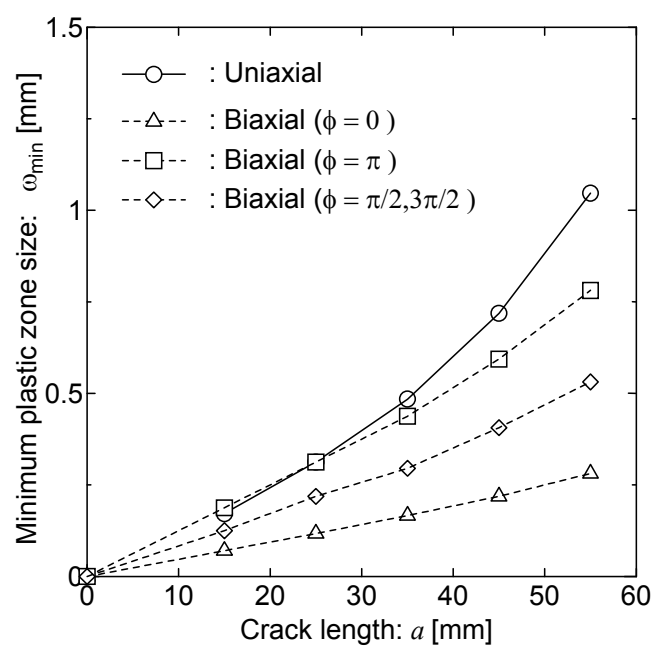

b) At the minimum loading,

$\Delta \sigma_{x 0} / \Delta \sigma_{y 0}=1$.

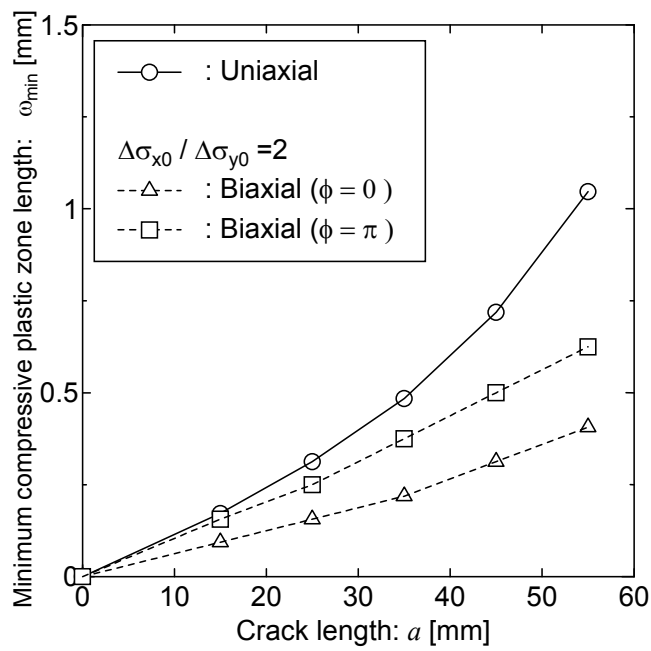

d) At the minimum loading,

$\Delta \sigma_{x 0} / \Delta \sigma_{y 0}=2$.

Fig.11 Plastic zone size growth histories. 


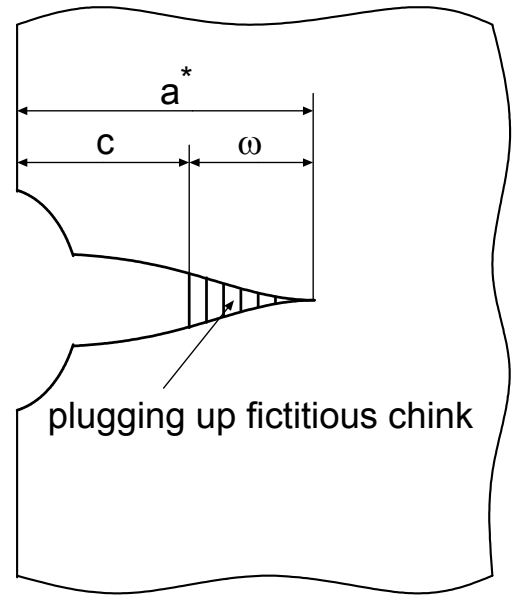

a) Crack surface displacement for fictitious crack.

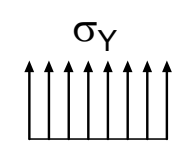

applied uniform yield stress state

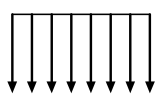

$\sigma_{Y}$

b) Segment plugged up region with fictitious COD in plastic zone.

Fig.12 Schematic illustration of the crack surface displacements for the fictitious crack from the strip yield model and the approximation of the physical COD.

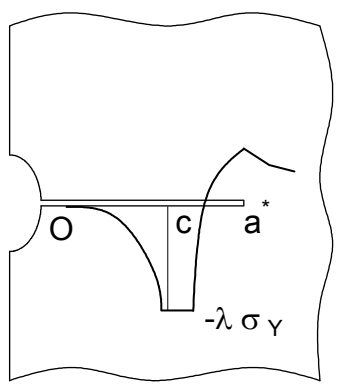

(a)

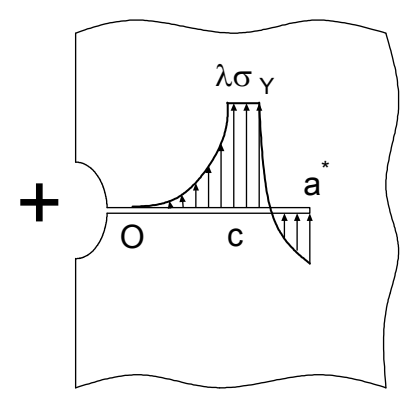

(d)

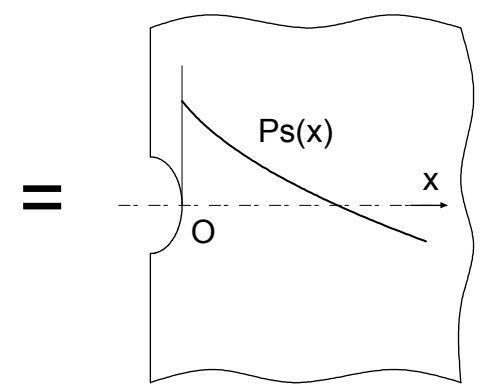

(b)

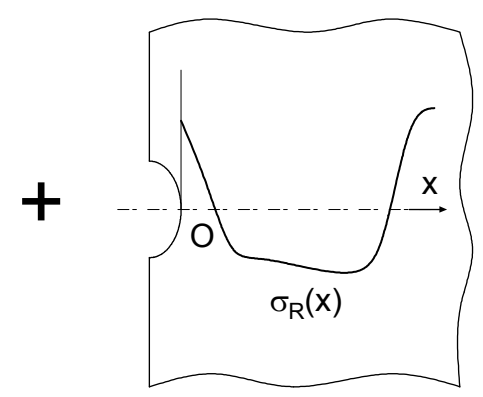

(e)

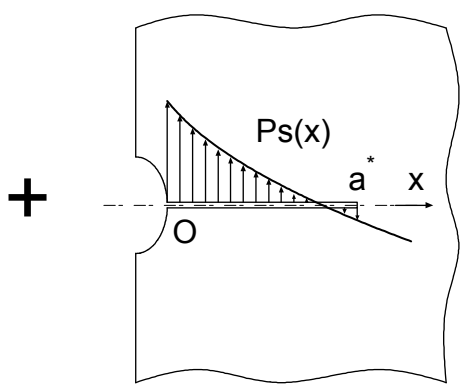

(c)

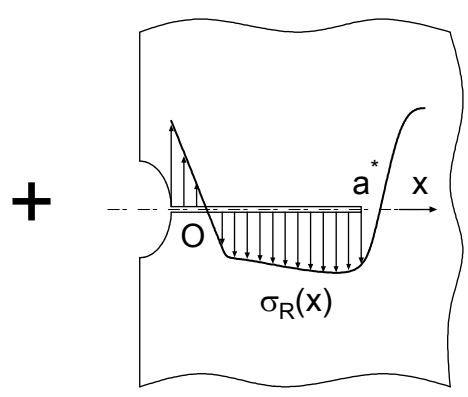

(f)

Fig.13 Application of the superposition principle to computed COD in the plastic zone embedded in the previous plastic zone. 


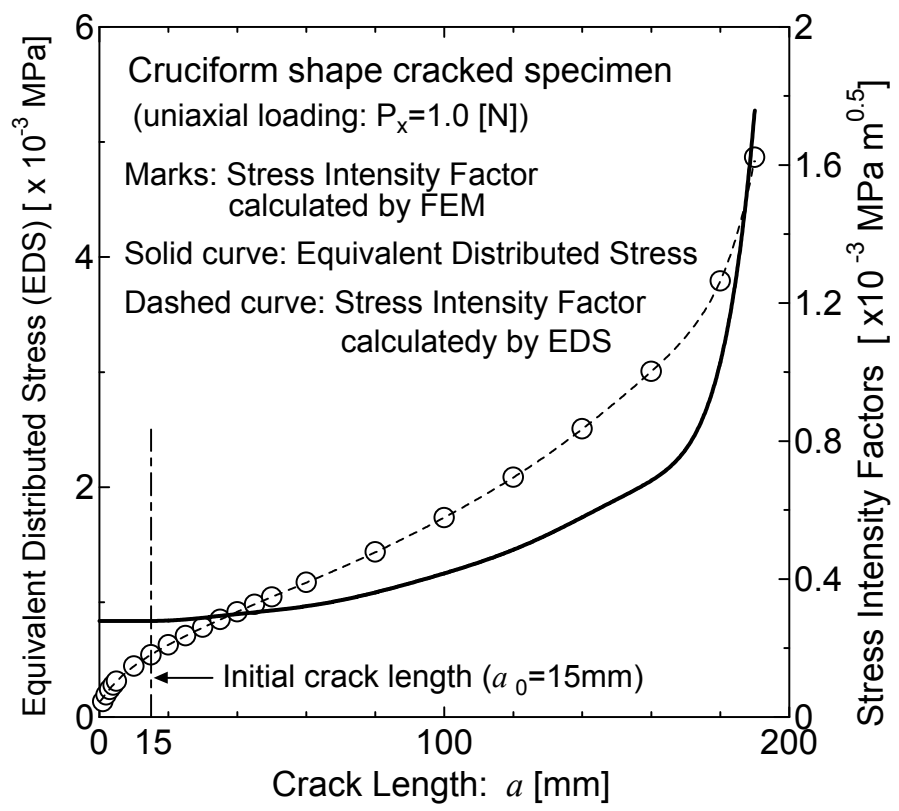

Fig.14 Equivalent distributed stress (EDS) under uniaxial loading condition of the cruciform shape cracked specimen used. 


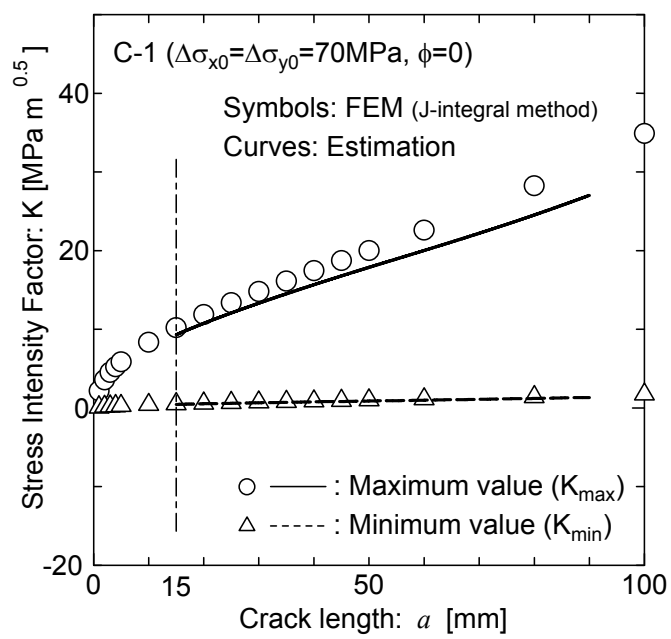

a) $\mathrm{C}-1$

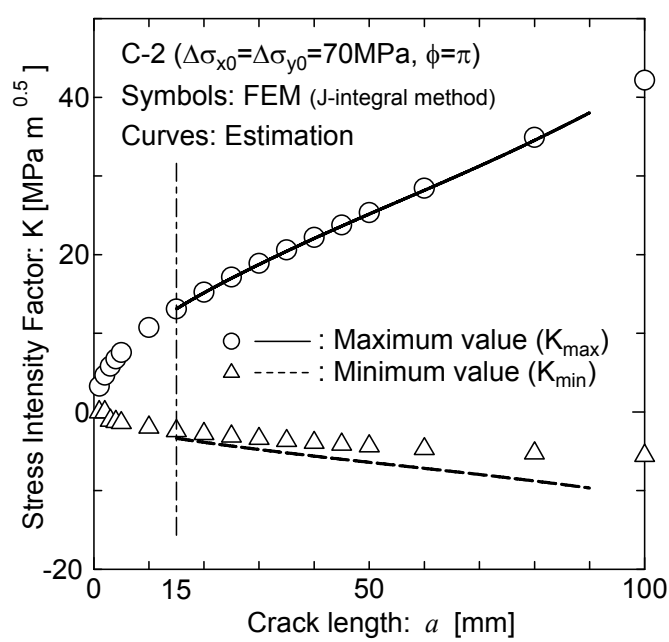

b) $\mathrm{C}-2$

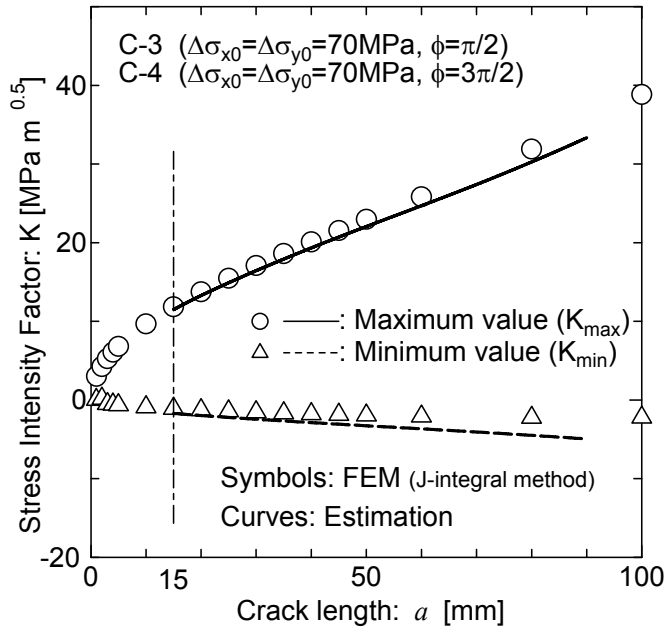

c) $\mathrm{C}-3, \mathrm{C}-4$

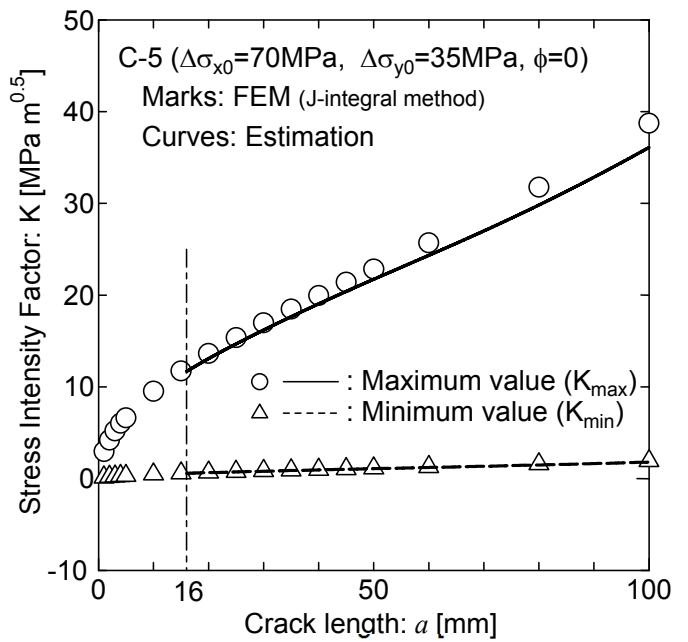

d) $\mathrm{C}-5$

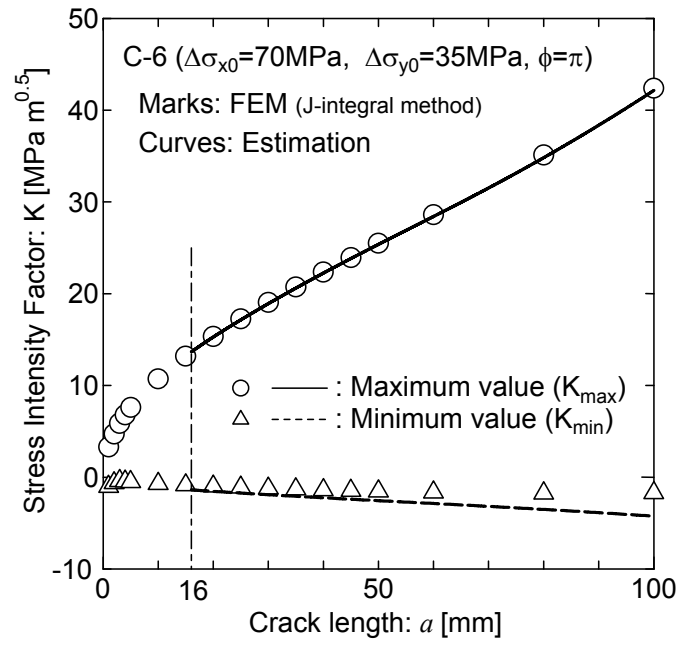

e) C-6

Fig.15 Comparisons of stress intensity factor histories based on EDS approximations with FE analyses. 


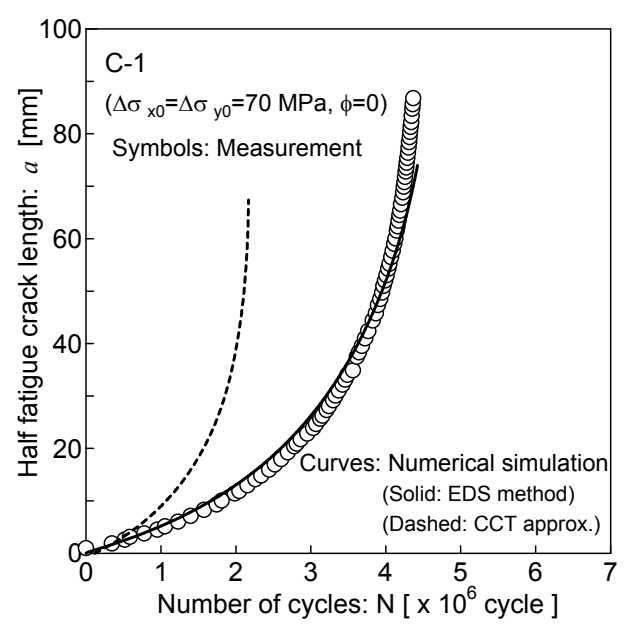

a) $\mathrm{C}-1$

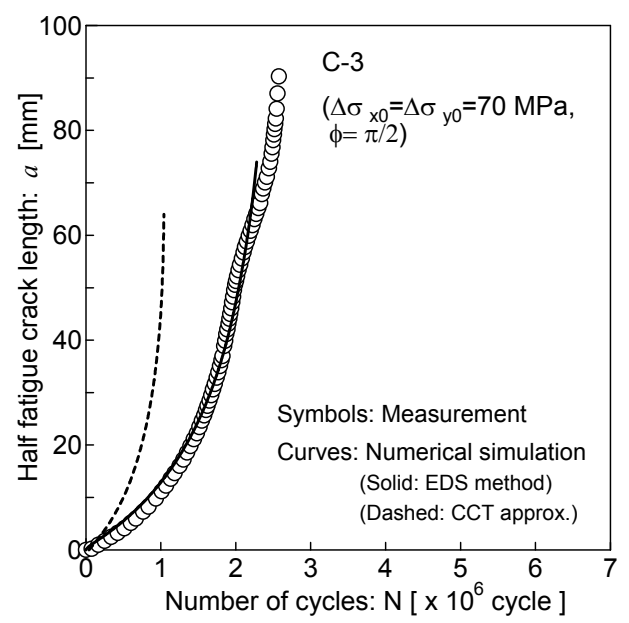

c) $\mathrm{C}-3$

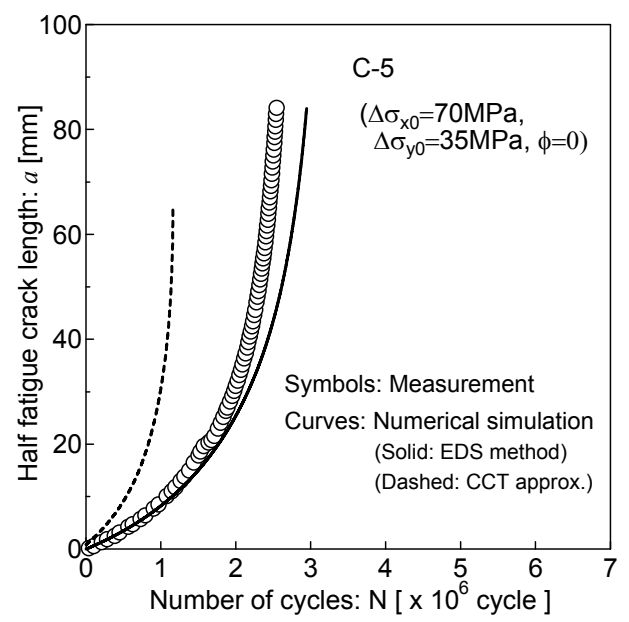

e) C-5

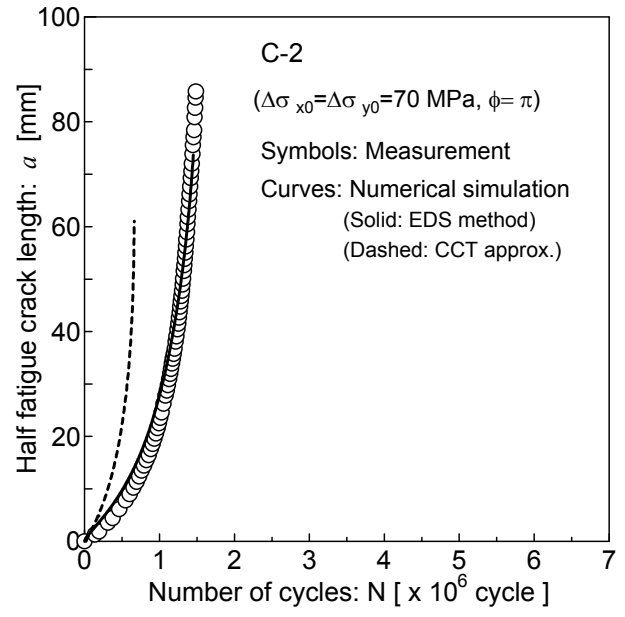

b) $\mathrm{C}-2$

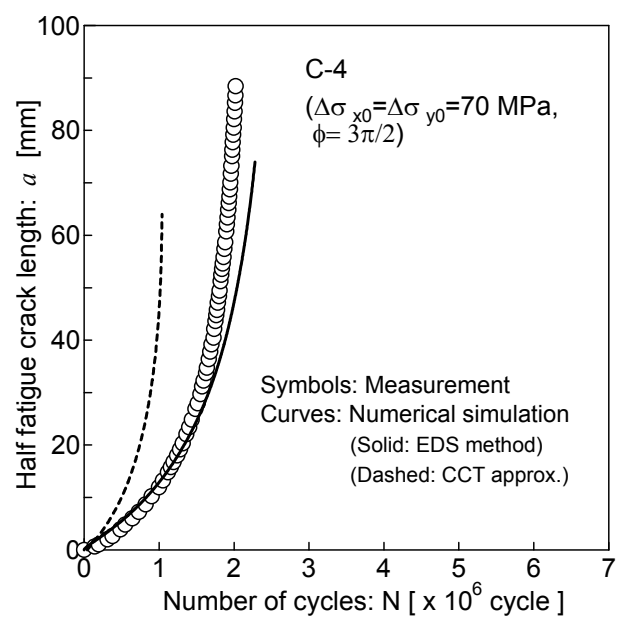

d) $\mathrm{C}-4$

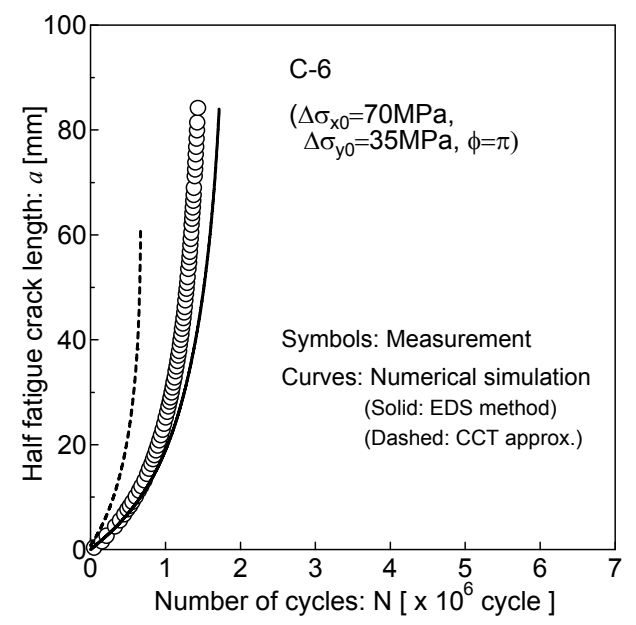

f) $\mathrm{C}-6$

Fig. 16 Comparison between estimated fatigue crack propagation histories by the EDS method and CCT specimen approximation with measured values. 
Table 1 Mechanical Properties and chemical composition of tested material (ClassNK: grade KA).

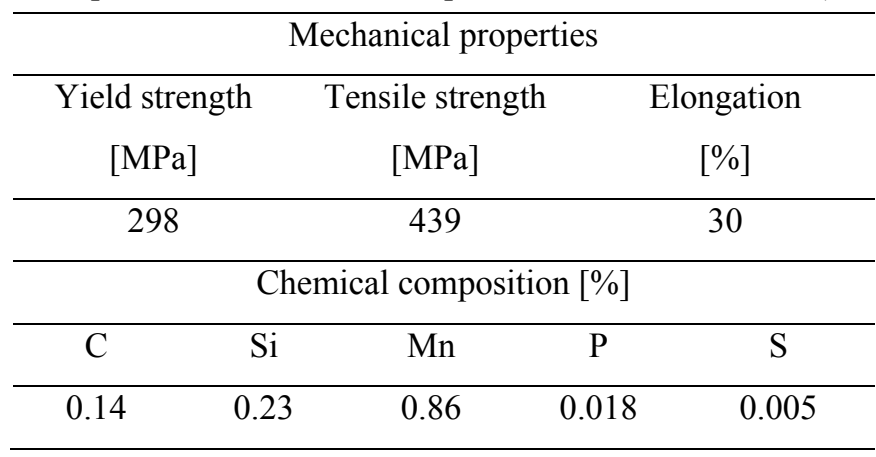

Table 2 Applied loading conditions

\begin{tabular}{|c|c|c|c|c|}
\hline Test ID & $\sigma_{x 0} \min / \sigma_{x 0} \max$ & $\Delta \sigma_{x 0}[\mathrm{MPa}]$ & $\Delta \sigma_{y 0}[\mathrm{MPa}]$ & $\phi[\mathrm{rad}]$ \\
\hline C-1 & \multirow{7}{*}{0.05} & \multirow{7}{*}{140} & \multirow{4}{*}{140} & 0 \\
\hline $\mathrm{C}-2$ & & & & $\pi$ \\
\hline $\mathrm{C}-3$ & & & & $\pi / 2$ \\
\hline C-4 & & & & $3 \pi / 2$ \\
\hline $\mathrm{C}-5$ & & & \multirow{2}{*}{70} & 0 \\
\hline C-6 & & & & $\pi$ \\
\hline $\mathrm{CCT}$ & & & N. A. & N. A. \\
\hline
\end{tabular}

(Notes)

$\sigma_{x 0}{ }^{\min }$ : applied remote minimum stress component normal to the crack line

$\sigma_{x 0}{ }^{\max }$ : applied remote maximum stress component normal to the crack line

$\Delta \sigma_{x 0}: \quad$ applied remote stress range of $x$ component

$\Delta \sigma_{y 0}: \quad$ applied remote stress range of $y$ component

$\phi: \quad$ phase difference of biaxial loading

CCT : uniaxial test used by CCT specimen shown in Fig.2. 